\title{
Z-Score for Bankruptcy Forecasting of the Companies Producing Building Materials
}

\author{
Burganova R. A. ${ }^{1} \&$ Salahieva M. F. ${ }^{1}$ \\ ${ }^{1}$ Kazan Federal University, Institute of Management, Economics and Finance, Kazan, Russia \\ Correspondence: Salahieva M. F., Kazan Federal University, Institute of Management, Economics and Finance, \\ Kazan, 420008, Russia. Tel: 7-843-291-1360. E-mail: Albert171@yandex.ru
}

Received: December 27, 2014 Accepted: February 19, 2015 Online Published: April 30, 2015

doi:10.5539/ass.v11n11p109 URL: http://dx.doi.org/10.5539/ass.v11n11p109

\begin{abstract}
The article is dedicated to developing of methodological basis for the probability of enterprises' bankruptcy forecasting. The authors have identified the reasons of the existing bankruptcy forecasting models failure, the necessity of models developing for companies in various industries on the basis of the existing instruments. As a result of the multivariate discriminate analysis we offer Z-scores based on the average annual rates of change and taking into account the peculiarities of the industry companies. The model is developed for companies specializing in the production of building materials, it has a high level of productivity $-90.4 \%$.
\end{abstract}

Keywords: region's economic area, regional competition, regional competitive advantages, competitive positioning, economic activities, industrial enterprise's resource potential, economic area "growth points"

\section{Introduction}

The high level of competition and the unstable economic environment necessitate the use of crisis management instruments. One of the information sources for the development and implementation of preventive tactical measures providing the reduction of the enterprises' insolvency risk are the results of the bankruptcy forecasting models (Ravi Kumar \& Ravi, 2007; Shuang, Yuan, Zhang, \& Yu, 2011; Yakupova \& Absalyamova, 2014). Systematization of research on the application of bankruptcy forecasting methods is presented in the work by Ravi Kumar, P., Ravi, V. (Nasir, John, Bennett, \& Russell, 2000) dealing with the following classification: (i) statistical techniques, (ii) neural networks, (iii) case-based reasoning, (iv) decision trees, (iv)operational research, (v) evolutionary approaches, (vi) rough set based techniques, (vii) other techniques subsuming fuzzy logic, support vector machine and isotonic separation and (viii) soft computing subsuming seamless hybridization of all the above-mentioned techniques.

Feng Yu Lin, McClean, S. offered a data mining approach to the forecasting of corporate failure and proved, that a hybrid method produces higher forecasting accuracy than individual classifiers (Burganova, Novak, \& Salahieva, 2014).

Problems of application, advantages and disadvantages of AdaBoost and neural networks are presented in the works (Alfaro, García, Gámez, \& Elizondo, 2008; Azmitov, Ivanovskiy, \& Korabelnikova, 2014). Dimitras, A. I., Slowinski, R., Susmaga, R., Zopounidis, C. (1999) offer to use rough sets. Du Jardin, P., Séverin, E. suggested to use a Kohonen map to increase the forecasting horizon of a financial failure model (2011).

Despite the great diversity of approaches and methods for the forecasting of bankruptcy the greatest preference is often given to the quantitative, based on statistical methods.

Balcaen, S., Ooghe, H. investigated the classic statistical business failure forecasting models and their related problems (2006), Shuang, Q., Yuan, Y., Zhang, M., Yu, D. described based on Fisher's Linear Discriminant Analysis (2012).

As supporters of quantitative methods, we agree with the researchers, who suppose that the Z-scores and R-accounts stipulating the use of the absolute values of the coefficients cannot bear universal character. Simultaneous application of different "universal" models often leads to the opposite results, which casts doubt on their practical significance.

The results obtained by the existing models have turned out to be multidirectional due to a number of circumstances. 
Firstly, due to the quality of the sampling in the formation of models. Large volume of samples regardless of industrial and regional characteristics cannot be sufficient grounds for the formation of the model. Large disparities in the development of industries within the same region, different structure of assets, marketable products and its consumption require sampling of businesses from the sample industry, and, if possible, within the limits of one region.

Secondly, due to the indexes used for the forecast development. All models for bankruptcy probability forecasting include financial indicators, application of which in general is reasonable, as they reflect the company's performance efficiency.

However, the coefficients in the models calculated on the basis of the financial statements are momentary and do not reveal the "history" of the company, which may affect its current state.

Thirdly, due to the different time aspect of developing (sampling) and the model application. In the formation and subsequent application of the model one cannot exclude the influence of the economic cycle stage (meaning long and medium waves). The capital structure change towards the predominance of the borrowed sources is characteristic of the growth stage, for a maturity stage - the growth of asset turnover will be quite normal, for the decline stage - the reduction of liquidity ratios, etc. In this connection, it is necessary to take into account the relevance of the model used for the current stage of the cycle.

Thus, currently preserved urgency of development of modern economic and mathematical models to predict the bankruptcy of companies.

\section{Method}

Analysis of existing methods for the probability of bankruptcy forecasting (methods based on deterministic analysis, qualitative methods, methods of discriminate analysis) confirms the appropriateness and feasibility of the multivariate discriminate analysis application for models development.

1. Sampling of the similar companies, considering both bankrupt enterprises, and those avoided the bankruptcy

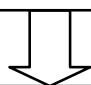

2. Determination of indexes characterizing financial status of the enterprise

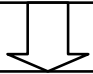

3. Calculation of indexes and their average annual growth rate by every company and presentation of the original data in the formal constructions

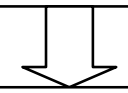

4. Discriminate (classifying) function development and its identification

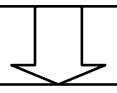

5. Statistic evaluation of distribution parameters for the discriminate function determination

6. Forecasting ability of the model determination
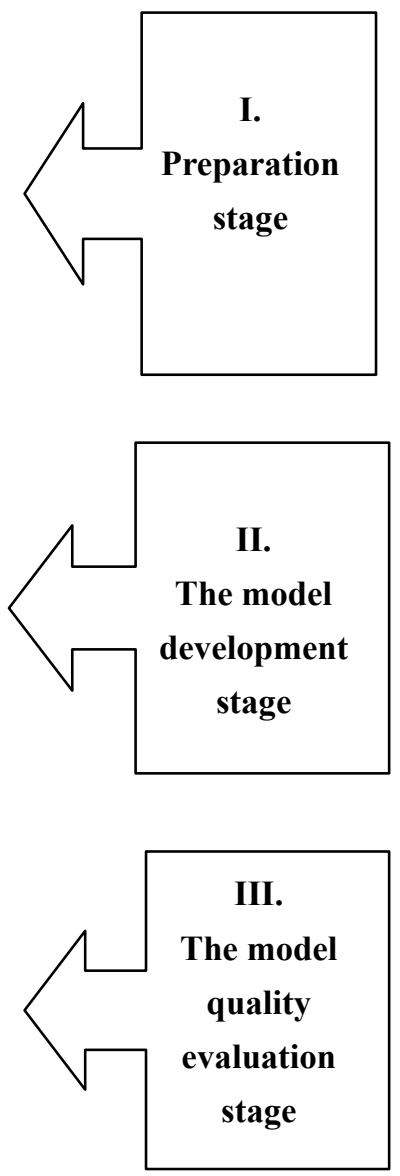

Figure 1. Stages of the diagnostics and forecasting model of bankruptcy probability development 
Construction of Z-models based on the discriminate analysis involves the separation of companies by their sampling into two classes - the companies subject to bankruptcy, and the ones able to avoid it, by way of the classifying of functions modeling in the form of the correlation model. The task is to draw up an equation with specific discriminate boundary, which allows to divide the system of indicators for such their combination in which the risk of the company's bankruptcy is high or vice versa. Our study makes the attempt to take into account these deficiencies of the bankruptcy forecasting models indicated above in the process of discriminate analysis application. The proposed model takes into account the industrial and regional characteristics, as it is developed on the basis of the data obtained from the enterprises producing building materials in the Republic of Tatarstan (Lin \& McClean, 2001).

The model development stages are represented on the Figure 1.

The sampling has been made at the first stage from the 52 companies of the analyzed industry. 26 companies turned to be relative stable, and the 26 remaining ones were within the bankruptcy proceedings.

Discriminate analysis allows to determine the level of dependency between the set of variables and the company status (bankrupt - not bankrupt). The main indexes characterizing the financial status have been calculated for all companies (liquidity and solvency indexes, as well as financial sustainability, efficiency, business activity - 21 indexes in all).

The forecast has been developed based of the number of years' data analysis preceding the bankruptcy procedure (2007-2009). Thus, we have determined the financial coefficients for each company, and calculated the average annual growth rate of these variables, which allowed us to divide the analyzed set into groups by the level of financial state of the companies.

The model was developed on the second stage of the multivariate discriminate analysis carried out with the help of the software complex STATISTICA 6.0. The analysis was made using the step by step method with exclusion of the tolerant level under the minimal values $(\mathrm{T})$ 0,01. The exclusion of variables from the model has been determined by the F-criterion value. Each step manifested the exclusion from the model of variables with the smallest value of this index.

The next step by step discriminate analysis with exclusion allowed to determine five variables, which reflected most precisely the separation degree of two studied groups (Table 1), and to develop two classifying functions $(1,2)$.

Table 1. Formulas of indexes for model of bankruptcy forecasting

\begin{tabular}{|c|c|}
\hline Name of the index & Formulas \\
\hline Quick liquidity coefficient & $\begin{array}{c}\text { Monetary assets }+ \text { Short-term receivables / Current } \\
\text { liabilities }\end{array}$ \\
\hline $\begin{array}{l}\text { Borrowed and internal funds correlation } \\
\text { coefficient }\end{array}$ & $\begin{array}{c}\text { Long-term liabilities }+\begin{array}{l}\text { Short-term liabilities / Internal } \\
\text { capital }\end{array}\end{array}$ \\
\hline Return on assets coefficient & Net revenue (loss) / Annual average assets price \\
\hline Return on sales coefficient & Revenues (losses) of sales / proceeds \\
\hline Assets turnover coefficient & Proceeds / Annual average assets price \\
\hline
\end{tabular}

$$
\begin{aligned}
& \mathrm{Z} 1=2,237 \times \mathrm{X} 1+3,241 \times \mathrm{X} 2+1,286 \times \mathrm{X} 3-6,105 \times \mathrm{X} 4+3,135 \times \mathrm{X} 5-3,48, \\
& \mathrm{Z} 2=1,756 \times \mathrm{X} 1-1,538 \times \mathrm{X} 2+2,13 \times \mathrm{X} 3+2,659 \times \mathrm{X} 4+4,287 \times \mathrm{X} 5-3,012,
\end{aligned}
$$

where: $\mathrm{X} 1$ - Annual average growth rate of quick liquidity coefficient;

$\mathrm{X} 2$ - Annual average growth rate of borrowed and internal funds correlation coefficient;

$\mathrm{X} 3$ - Annual average growth rate of return on assets coefficient;

X4 - Annual average growth rate of return on sales coefficient;

X5 - Annual average growth rate of assets turnover coefficient;

Z1- Complex index characterizing the high level of the company failure risk;

$\mathrm{Z} 2$ - Complex index characterizing the low level of the company failure risk. 
Each analyzed company will belong to the class, for which the classified function value is maximal.

That is, the company will be the potential bankrupt, if $\mathbf{Z 1}>\mathbf{Z 2}$.

The models quality evaluation is carried out on the third stage of the research.

The separating ability quality of the received functions has been evaluated based on the indexes Wilks lambda $(\lambda), F$-statistics criterion value and the level of its value (p).

The indexes Wilks lambda data equal to 0,01764 and the value of F- criterion equal to 51,633 you allow to make a conclusion, that the fulfilled classification is proper enough.

The acquired functions value analysis has been carried out by the indexes represented in the Table 2 .

Table 2. The main statistics of the functions' value

\begin{tabular}{cc}
\hline Statistic's name & Statistic's value \\
\hline Internal value of discriminate function & 1,8210 \\
Canonical correlation (R) & 0,7097 \\
Wilks lambda (X) & 0,2701 \\
Statistics $-X 2$ & 51,347 \\
Value level & $5,1 \times 10^{-9}$ \\
\hline
\end{tabular}

Basing on the indicated values we can affirm the good separating ability of the developed models, functions value and the difference between the investigated groups, as well as the high grade of dependence between the variables values mass included into the function and the studied variety of groups.

\section{Result}

Models testing for companies sampling allows to determine their reliability by the consequent comparative analysis of the results. On the basis of the fulfilled comparison it becomes possible to recommend those models for application, which are the most appropriate to the peculiarities of the building materials production industry.

For comparative analysis we have chosen the most oftenly used models: Taffler model (Agarwal \& Taffler, 2008; Agarwal \& Taffler, 2007); Liss model; five factors model of Altman, 1983 (Altman, 1993).

Together with the above named models we have analyzed the offered model of bankruptcy forecasting (1), (2), developed on the basis of the building materials production companies in the Republic of Tatarstan.

The results of the models testing are represented in the Table 3.

Table 3. The results of testing of the discriminate models' forecasting ability

\begin{tabular}{ccccc}
\hline $\begin{array}{c}\text { The results of forecasting } \\
\text { ability testing }\end{array}$ & Actual status of the company & \multicolumn{2}{c}{$\begin{array}{c}\text { Forecast by the model } \\
\text { Bankrupt }\end{array}$} & $\begin{array}{c}\text { Forecast } \\
\text { accuracy, \% }\end{array}$ \\
\hline \multirow{3}{*}{ Taffler model } & Bankrupt & 6 & 20 & 61,5 \\
& $\begin{array}{c}\text { Not Bankrupt } \\
\text { General accuracy of the model }\end{array}$ & 7 & 19 & 73,1 \\
forecasting & $\mathrm{X}$ & $\mathrm{X}$ & 67,3 \\
Liss model & Bankrupt & 20 & 6 & 76,9 \\
& Not Bankrupt & 8 & 18 & 69,3 \\
& General accuracy of the model & $\mathrm{X}$ & $\mathrm{X}$ & 71,1 \\
five factor model of & forecasting & 24 & 2 & 92,3 \\
Altman,1983 & Not Bankrupt & 12 & 14 & 53,8 \\
& General accuracy of the model & $\mathrm{X}$ & $\mathrm{X}$ & 73,1 \\
forecasting & Bankrupt & 23 & 3 & 88,46 \\
& Not Bankrupt & 2 & 24 & 92,31 \\
& General accuracy of the model & $\mathbf{2 5}$ & $\mathbf{2 7}$ & $\mathbf{9 0 , 3 9}$ \\
\hline
\end{tabular}


According to the Taffler model, if the value of $Z>0,3$ it means that the company has good long-term prospects, if $Z<0,2$, then bankruptcy is more than likely.

This study allowed us to estimate a weak forecasting level of the model. This is evidenced by the virtual absence of the ability of the model with respect to classifying of bankrupt companies. At the same time, in $73.1 \%$ of cases the model is able to recognize companies with good financial status. Total forecasting ability of the model has comprised $67.3 \%$, which is indicative of a dubious character of this model application in assessing of insolvency forecast regarding companies in the investigated industry.

The limit value of the index, according to the Liss model, equals to 0.037 . If $Z>0,037$ probability of bankruptcy will be low, if less - then the probability is high. According to the data acquired in the study, the overall predictive level of the Liss model comprises $75 \%$. This is an average result. The homogeneity of the acquired results is worth noting. During testing it has been found out that the probability of a proper bankruptcy forecasting is equal to a positive assessment of the financial status and both equal to $75 \%$. This demonstrates the classifying function ability.

The criterion of bankruptcy by the considered $\mathrm{E}$. Altman model is $\mathrm{Z}<1,23$; while the interval $1,23<\mathrm{Z}<2,9$ - is an area of uncertainty, and by $Z>2,9$ - the probability of bankruptcy is negligible. Predictive power of the model comprises $88 \%$. In $75 \%$ of cases the model recognizes the studied organization as a bankrupt. In this case, the analysis of testing results reveals the absence of a stable separation ability of the function. This is evidenced by the level of the mismatch index of forecasted and actual data for organizations with a good prospect of financial status.

Under the offered model of bankruptcy forecasting based on the companies in the industry of building materials production, each organization investigated separately will be referred to the special class, where the classified value of the function will reach its maximum.

With a sufficiently high probability $(88.5 \%)$ it could be affirmed, that in the event $\mathrm{Z}$ value matches into the designated interval, the organization will become a bankrupt in the coming year. Herewith, it is worth noting, that $92.3 \%$ - is a very high probability level of correct prediction for bankruptcy avoidance.

\section{Conclusions}

High reliability of acquired models has been predetermined by the following factors: the models have been originally designed for enterprises of the Republic of Tatarstan, based on the data from official reports; they take into account the macroeconomic environment, industry-specific activity of the enterprises, dynamics of the company performance indexes.

Approbation of the studied model based on the annual average growth rate of indicators change showed a high predictive level - 90.4\%.

The relevance of the model at present is also supported by the results obtained from processing the data acquired from a number of enterprises producing building materials in the Republic of Tatarstan in 2010-2013.

Evaluation of test results allows to recommend this model in the risk of bankruptcy of enterprises forecasting in the considered industry. Here it should be noted that such models based on dynamic indicators should be developed separately for the companies in other industries.

The information on economic entities by economic activities accumulated in the fiscal authorities should be maximally used for these purposes in sector surveys, analysis of relevant markets, identifying of trends, including for the development of predictive models of insolvency (bankruptcy) of enterprises.

We believe that it is the centralization of data collection, processing, forming, testing and updating of bankruptcy forecasting models efforts, which will eliminate the reasons of the models failure.

\section{References}

Agarwal, V., \& Taffler, R. (2007). Twenty-five years of the Taffler z-score model: Does it really have predictive ability? Accounting and Business Research, 37(4), 285-300. http://dx.doi.org/10.1080/00014788.2007. 9663313

Agarwal, V., \& Taffler, R. (2008). Comparing the performance of market-based and accounting-based bankruptcy prediction models. Journal of Banking and Finance, 32(8), 1541-1551. http://dx.doi.org/ 10.1016/j.jbankfin.2007.07.014

Alfaro, E., García, N., Gámez, M., \& Elizondo, D. (2008). Bankruptcy forecasting: An empirical comparison of AdaBoost and neural networks. Decision Support Systems, 45(1), 110-122. http://dx.doi.org/10.1016/j.dss. 
2007.12.002

Altman, E. I. (1993). Corporate Financial Distress and Bankruptcy: A Complete Guide to Predicting and Avoiding Distress and Profiting from Bankruptcy (p. 356).

Azmitov, R. R., Ivanovskiy, I. A., \& Korabelnikova, L. L. (2014). Features of Russian Companies Real Estate Appraisal in the Accounting System. Mediterranean Journal of Social Sciences, 5(24), 242-245.

Balcaen, S., \& Ooghe, H. (2006). 35 years of studies on business failure: An overview of the classic statistical methodologies and their related problems. British Accounting Review, 38(1), 63-93. http://dx.doi.org/10.1016/j.bar.2005.09.001

Burganova, R. A., Novak, V. V., \& Salahieva, M. F. (2014). Analysis of Using Capital Asset Pricing Model for Assessing Companies Return. Mediterranean Journal of Social Sciences, 5(24), 246-250.

Dimitras, A. I., Slowinski, R., Susmaga, R., \& Zopounidis, C. (1999). Business failure prediction using rough sets. European Journal of Operational Research, 114(2), 263-280. http://dx.doi.org/10.1016/S0377-2217 (98)00255-0

Du Jardin, P., \& Séverin, E. (2011). Predicting corporate bankruptcy using a self-organizing map: An empirical study to improve the forecasting horizon of a financial failure model. Decision Support Systems, 51(3), 701-711. http://dx.doi.org/10.1016/j.dss.2011.04.001

Lin, F. Y., \& McClean, S. (2001). A data mining approach to the prediction of corporate failure. Knowledge-Based Systems, 14(3-4), 189-195. http://dx.doi.org/10.1016/S0950-7051(01)00096-X

Nasir, M. L., John, R. I., Bennett, S. C., \& Russell, D. M. (2000). Predicting corporate bankruptcy using modular neural networks. IEEE/IAFE/INFORNS 2000: 6th Conference on Computational Intelligence for Financial Engineering (CIFEr) (pp. 86-91).

Nikolayeva, L., \& Salakhieva, M. (2012). Development of diagnostics and forecasting models of the company bankruptcy probability. Audit and financial analysis, 3, 178-186.

Ravi Kumar, P., \& Ravi, V. (2007). Bankruptcy prediction in banks and firms via statistical and intelligent techniques. European Journal of Operational Research, 180(1), 1-28. http://dx.doi.org/10.1016/j.ejor. 2006.08.043

Shuang, Q., Yuan, Y., Zhang, M., \& Yu, D. (2011). Bankruptcy prediction in construction companies via Fisher's Linear Discriminant Analysis. International Conference on E-Business and E-Government (pp. 2100-2103).

Yakupova, N., \& Absalyamova, S. (2014). Assesment and management of enterprise value. SGEM International multidisciplinary scientific conference of social sciences and arts (pp. 51-58). http://dx.doi.org/10.5593/ sgemsocial2014/B24/S7.007

\section{Copyrights}

Copyright for this article is retained by the author(s), with first publication rights granted to the journal.

This is an open-access article distributed under the terms and conditions of the Creative Commons Attribution license (http://creativecommons.org/licenses/by/3.0/). 